Bond University

Research Repository

\title{
Does Lecture Capturing Impact Student Performance and Attendance in an Introductory Accounting Course?
}

Aldamen, Husam; Al-Esmail, Rajab; Hollindale, Janice

Published in:

Accounting Education

DOI:

10.1080/09639284.2015.1043563

Licence:

Other

Link to output in Bond University research repository.

Recommended citation(APA):

Aldamen, H., Al-Esmail, R., \& Hollindale, J. (2015). Does Lecture Capturing Impact Student Performance and Attendance in an Introductory Accounting Course? Accounting Education, 24(4), 291-317.

https://doi.org/10.1080/09639284.2015.1043563

\section{General rights}

Copyright and moral rights for the publications made accessible in the public portal are retained by the authors and/or other copyright owners and it is a condition of accessing publications that users recognise and abide by the legal requirements associated with these rights.

For more information, or if you believe that this document breaches copyright, please contact the Bond University research repository coordinator. 


\title{
Does Lecture Capturing Impact Student Performance and Attendance in an Introductory Accounting Course?
}

\begin{abstract}
The study empirically examines the interplay between lecture capturing viewership, performance and attendance for students in the Middle Eastern country of Qatar. The sample consists of 254 students enrolled in an introductory accounting class either in the Fall or Spring semesters. We show a weak positive relationship between lecture capturing and performance especially in the presence of more traditional explanatory variables such as GPA, attendance, gender and seniority. However, we do not find that lecture capturing reduces attendance. Actual performance results are contrasted with students' perception of the usefulness and effectiveness of lecture capturing. Survey responses reveal that, overall, students attribute a great deal of credit to this pedagogical resource. They stated that lecture capturing clarifies concepts discussed in class, assists in studying for exams, enhances exam results and increases interest in the course. We find significant differences between low performing students and others when it comes to viewing recorded lectures during the same week that those lectures were presented in class. Another important difference is their perception of attendance. The results indicate that the majority of low performing students believe lecture capturing to be a substitute for attending traditional face-to-face lectures.
\end{abstract}




\section{Introduction}

Technology advances have produced numerous devices with which to access online resources anywhere an internet connection exists (Holtzblatt and Tschakert, 2011). By making use of these digital innovations, educators have set out to catapult the student learning experience via transformation of the traditional educational landscape. One of the most notable developments in recent years is recording live lectures and then making them available for student access. Although audio and video lecture capturing has been in use for many years (Secker, Bond and Grussendorf, 2010), it is only recently that educational institutions have incorporated them into their pedagogical tool box on a much wider scale. Universities such as Cornell, MIT, Wharton, Stanford and Berkeley have used Blackboard technology as a platform through which captured lectures are made available to users (Holtzblatt and Tschakert, 2011). Citing the experiences of Wilson and Wilson (2010), Holtzblatt and Tschakert (2011) describe the many benefits of lecture capture, stating that students are allowed to learn at their own speed, and can stop the video and rewind as things become more complex. Additionally, they claim that using technology to export traditional classroom content onto the internet allows greater coverage of material while maintaining indepth conversations in class. Finally, they suggest that students are more engaged, and attendance is not affected by online lectures.

Although there are convincing arguments in favour of adopting lecture capturing, legitimate concerns about the impact this technology might have on student performance and attendance must be acknowledged. Studies such as Traphagan, Kucsera, and Kishi (2010) and Shaw and Molnar (2011) show that lecture capturing is useful and improves student performance. However, the majority of prior research provides evidence suggesting that lecture capturing is unrelated to performance (Brotherton and Abowd, 2004, Dey, Burn and Gerdes, 2009, Euzent, Martin, Moskal and Moskal, 2011, Ford, Burns, Mitch and Gomez, 
2012, McNulty, Hoyt, Gruener, Chandrasekhar, Espiritu, Price and Naheedy, 2009, Owston, Lupshenyuk and Wideman, 2011, Settle, Dettori and Davidson, 2011, Zupancic and Horz, 2002). From a pedagogical viewpoint, a question must be raised as to whether using lecture capturing as a substitute for, or supplement to, attending in-class lectures may have an adverse effect on student performance. This study attempts to answer this question by examining the viewership of captured lectures and how it relates to student performance and attendance for students enrolled in an introductory financial accounting course in the Middle Eastern country of Qatar. Furthermore, it offers insight into students' perception of this technology in terms of utility and usefulness.

We contribute to the existing literature on lecture capturing by examining the initial period in which lecture capturing technology is adopted, as well as the immediate subsequent period. This dual-period exploration provides a point of reference for the study which highlights possible variations in the results between the two periods. Furthermore, a comparison between the initial period at which the technology was adopted and the period immediately following could show both a learning curve and a more receptive attitude for users and administrators alike. Although it is unclear if past research that found no relationship between lecture capturing and student performance had selected the initial period of lecture capture implementation to be their period of interest, it could very well be a possibility that findings of a later period of study would differ.

There are two reasons why this study is of crucial importance. Firstly, it contributes to the fervently debated issue of using technological innovations to help students learn. Online student resources in education are on the rise in an atmosphere of uncertainty amongst users (both students and instructors). In particular, the debate on the overall cost-benefit of these resources remains unresolved with many citing lack of evidence to support either direction. On the one hand, lecture capturing could benefit the learning process by allowing students to 
view a lecture as many times as necessary until the intended learning outcome is achieved. However, on the other hand, it could be misused in the sense that it would replace many of the virtuous qualities of traditional learning that centre on face-to-face and interactive learning. The technology debate will, and should, continue until some level of clarity is achieved through empirical research.

The second reason for undertaking this study is that it deals with methods to improve teaching and learning processes in a vital introductory financial accounting course. According to Mladenovic (2000), negative stereotypes about accounting are often formed or strengthened in introductory accounting courses. Furthermore, this course is often a requirement for all business students prior to major selection and thus it could potentially play a significant role in their decision to specialize in accounting. Additionally, Introduction to Financial Accounting tends to be the foundation for more advanced accounting. The foundational nature of this course lends to the fact that students might be assisted by lecture capturing technology which will most likely impact their understanding of advanced accounting concepts and practices.

Freshman students tend to register for first-year courses such as Introduction to Financial Accounting. Younger learners tend to have different learning requirements and preferences relative to others (Singh, 2003). For example, The Millennial Generation or the Net Generation (Net Geners) have grown up in a digital and cyber environment and have distinctive ways of thinking, communicating and learning and make more conscious choices about the learning techniques that best suit them (Barnes, Marateo and Ferris, 2007). They are the most computer literate of all workforce entrants and, as students, their learning style is through multimedia (Nicholas, 2008). However, there is a risk that class attendance for younger learners will be compromised in favour of technological tools such a lecture capturing. Although Paisey and Paisey (2004) found an overall positive relationship between 
attendance and performance, Brocato (1989) illustrated that regular class attendance is a stronger determinant of academic success for younger college students than it is for other students. Holbrook and Dupont (2009), in their examination of class attendance and lecture capturing, found that younger, first-year students who would benefit the most from regular attendance are the ones who are more likely to rely on lecture capturing as a substitute for attendance. This finding has in part motivated the current study, which aims to investigate the usefulness effectiveness and utilisation of lecture capturing.

The primary focus of this study is to understand the impact of lecture capturing on performance and attendance. A sample of 254 first-year students enrolled in five sections of an Introduction to Financial Accounting course in either the Fall 2013 or Spring 2014 semester was used. Fall 2013 (Fall Semester) was the first time lecture capturing was used in the Introduction to Financial Accounting class. Spring 2014 (Spring Semester) represented the second time the course used this technology. The importance of using data from two consecutive semesters was to help control for glitches associated with the initial use of the technology during Fall Semester. By Spring Semester, captured lectures appeared, in general, to be "embedded" into the course design. As a result students, instructors and technicians were more aware of how to operate captured lectures than the previous semester.

In an effort to target differences amongst students, the sample was split into top, medium and low performing students. Our results suggest that low performing students viewed recorded lectures less frequently than other students. Additionally, there is no evidence of substitution effect in the relationship between lecture capturing and class attendance. In fact, students who attended more classes viewed more videos relative to other students. Furthermore, we show that there was a slight positive relationship between viewing captured lectures and performance. Nevertheless, the results for all tests were stronger and more significant for Spring Semester vis-à-vis Fall Semester. We interpret this result as the 
presence of a learning curve and students being more receptive to this type of pedagogy after the initial pilot phase in Fall Semester.

A secondary focus of this study is student feedback regarding the utilisation and effectiveness of lecture capturing. Students registered for Spring Semester answered twelve questions in an attempt to gauge their perception of lecture capturing. The results suggest an overwhelming positive impression of the technology. Overall, no statistically significant differences could be detected between low, medium and high performing students. However, one exception was the period in which the videos were viewed by students. The results suggest that low performing students had greater tendency to watch lecture captured video during the same week that the lecture was presented in class relative to others students. As for the issue of lecture capture effectiveness, the vast majority of students expressed that the new technology helped them understand the subject and enhanced their exam results. Once again, no statistically significant differences could be found when students were categorised in the three performance groups. Finally, when asked whether lecture capturing served as a substitute for attending class, the majority of students disagreed. However, a closer examination based on the three performance groups revealed that the majority of low performing students did, in fact, believe that lecture capturing could be used as a substitute for attending class.

The remainder of the paper proceeds as follows. Section two discusses prior literature and offers a theoretical base that supports the relationships between lecture capturing, student performance and attendance. Section three describes the research method used including the sample, variables and empirical methods used in the study. Section four presents the results of the data analyses. Finally, section five discusses the results and presents the conclusion, limitations and areas for future research.

\section{Literature Review and Hypotheses}


Information technology has reshaped the way we communicate, think and learn Duderstadt (2001). In higher education, online teaching and learning resources are increasingly being blended with traditional face-to-face pedagogies to accommodate the learning styles and expectations of today's digitally-savvy and technologically-equipped students. This move towards blended learning is due in part to technological advances in digital learning tools, and their increased availability to students.

Lecture capture technology, while only one component of the numerous learning approaches that comprise blended learning pedagogy, appears to be a popular means of supplementing traditional course delivery. It is one of the launching points from which follow more diverse, technology-based teaching and learning resources and tools such as blogs, You-Tube videos, podcasts, and interactive on-line material. There is evidence of lecture capture being used in various disciplines: financial accounting (Brecht and Ogilby, 2008, Taplin, Low and Brown, 2011); computer and digital media studies (Settle, et al., 2011); organic chemistry courses (Andrews, Brown, Harrison, Read and Roach, 2010); physics courses (Dey, et al., 2009); introductory economics (Euzent, et al., 2011); science courses in the medical field (McNulty, et al., 2009); anatomy and physiology courses for nursing students (Johnston, Massa and Burne, 2013); and European Law, and International Relations and International Organization courses (Wieling and Hofman, 2010). Furthermore, the range of lecture capture platforms used by higher education institutions is diverse, varying between resources developed in-house to those that are commercially available: Course Online (COL) (Settle, et al., 2011); Authoring on the Fly (Zupancic and Horz, 2002); Recollect (Brooks, Epp, Logan and Greer, 2011); MScribe (Herr, Bhatnagar, Goldfarb, Irrer, McKee and Neal, 2008); and eClass (Brotherton and Abowd, 2004); Blackboard (Andrews, et al., 2010); and Moodle and iTunes (Owston, et al., 2011).

One of the most compelling reasons for adopting lecture capture is to enhance student 
academic success. However, findings from prior studies regarding the influence of lecture capture systems on performance, typically measured by final grades for the subject being studied, are quite mixed. Brotherton and Abowd (2004) assessed an automated capture system, eClass, and its impact on various college courses in three universities over a period of three years. The study found eClass's impact on students' performance based on grades was not significant. McNulty et al. (2009) examined the relation between lecture capture utilisation and students' performance in undergraduate medical education. The results revealed that the majority of students $(60 \%)$ watched very few videos $(10 \%)$, with students tending to view lecture videos at home during weekends and prior to exams. Interestingly, students who had lower performance used the video lecture more than higher performers.

Dey, Burn and Gerdes (2009) studied the effects of offering different versions of video lectures online in comparison to the traditional classroom lectures in a physics course. They assigned a total of 280 students into three groups: personalized video, neutral video, and control group. The personalized video group watched pre-recorded online lectures with the video image of the lecturer, his voice, and slide presentation, while the neutral group had the audio of the lecturer synchronized with the slides only. The control group was given live lectures in a traditional classroom with the same lecturer and materials as the other two video groups. The study found that while students had more positive perceptions of the personalized video, there was no significant difference in the comprehension and recall of presented material between the online video groups and the live lecture group.

Owston et al. (2011) sought to contribute to the understanding of the relationship between lecture capture and academic performance, but with the intention of determining the benefits of investing in lecture capturing technology, given the financial constraints colleges face. They were not able to conclude that access to captured lectures actually leads to improved student performance. They suggested that while lecture capture resulted in less 
attendance on the part of students (10\% of students stopped attending lectures), there was no evidence to suggest that their grades suffered as a result. Viewing habits revealed that the majority of students accessed lecture recordings two or three times a week, but the grades were highest for those who accessed the lecture recordings once per month or less. The highest achieving students tended to fast-forward to sections, viewing them once, while the lowest achievers viewed the entire video multiple times. This research also determined that the availability of lecture recordings made no difference to in-class behaviour as the majority of students disclosed that they did not pay less attention in the in-class lecture. Euzent et al. (2011) assessed student performance and perceptions in two large introductory economics course sections over two semesters. One section was a traditional face-to-face class, while the other employed lecture capture. The study found no significant differences in student performance between the face-to-face lecture class and the class with an option to use video recorded lectures. The survey results suggested a positive perception of lecture capture, specifically its flexibility and convenience.

Ford et al. (2012) carried out a quasi-experiment to investigate differences in student perceptions, study strategies, and learning outcomes for university students who were exposed to classroom capture technology (CCT) as a supplement to a traditional lecturebased course, versus those who had no exposure to this resource. Their findings were that students exposed to CCT, relative to those with no exposure, were significantly more likely to report spending more hours studying, more likely to report that learning outcomes were effectively addressed, more likely to report that recorded class debates were useful, and more likely to report that they found that the course challenged them to do their best work. They found no difference in the final course grades between the two groups but warned that results might be different if all lectures had been made available via CCT. Johnston et al. (2013) conducted a quasi-experimental comparison between two groups of nursing students enrolled 
in the first anatomy and physiology course. One group had access to captured lectures while the other did not. The study found a weak relationship between access of recorded lectures and overall performance in the course. Students who had access to the recorded lectures showed significantly poorer overall academic performance.

There were also prior studies that provided opposing evidence, where lecture capture was found to have increased student performance. Traphagan et al. (2010) examined the impact of webcasts of class lectures on students' learning. Students, who were taught by the same instructor, were divided into two groups. The first group had access to the webcasts while the second did not. Their results suggest that viewing webcasts improved student performance. Furthermore, students reported positive feedback about the use of webcasts for learning purposes. Shaw and Molnar (2011) studied the usefulness of lecture capture in Podiatric medical education. The study examined student test scores in a biochemistry course for two classes, with lecture capture technology made available to only one of the classes. The results indicate that student performance in the class that used lecture capture was higher relative to the other class. Furthermore, non-native English speakers benefited more form the lecture capture technology than the native English speakers.

The objective of using lecture capturing as an educational tool is to improve student performance. Our premise is that a positive relationship exists between viewing recorded lectures and higher academic performance. We base our assumption on the idea that students can learn better if they can hear and see lectures more than once. Our argument is grounded in the cognitive theory of multimedia learning which stresses the power of words and pictures in the learning process (Mayer, Heiser and Lonn, 2001, Mayer and Moreno, 2003). According to Mayer (2009), cognitive theory is based on the concepts of dual-channels processing (i.e., visual and auditory processing), limited capacity for processing each channel, and active processing in order to achieve learning. Mayer (2009) suggests that the 
simultaneous seeing and hearing of presented information reduces students' cognitive loads and enhances their usage of working memory, which in turn leads to better learning outcomes. Lecture capturing allows asynchronous access to lecture material and thus provides students with the flexibility to choose a learning technique, allowing them to work within their individual processing capacity constraints. Students are able to watch recorded lectures at a convenient time and place, at their own pace, and are able to skip or replay sections according to their individual cognitive capacity.

According to Mayer (2009) active learning is a process of model building, a construction that makes sense of incoming material, which takes place when a student applies cognitive processes to this received material. Mayer (2009) described the three essential cognitive processes for active learning as selecting relevant material, organizing relevant material, and integrating relevant material with existing knowledge. The inherent flexibility of lecture capturing enhances a student's capability to process relevant material this way. Thus we posit that as lecture capture provides material in a multimedia format, it is conducive to active learning which ultimately influences a student's performance in the subject where it is offered. We also propose that viewership of captured lectures differs amongst top, medium and low performing students. The following hypotheses state the proposed relationship between lecture capturing and performance.

\section{H1: Viewership of recorded lectures differs amongst top, medium and low performing students.}

\section{H2: Viewing recorded lectures improves student performance.}

The second focus of the study is the relationship between lecture capturing and student attendance. Lecturers often cite possible decrease in student attendance as a negative effect of lecture capturing. This apprehension about attendance is evidenced by prior 
research, which found that lecture capturing has impacted negatively on student attendance (Johnston, et al., 2013, Owston, et al., 2011). Chang (2007) identified attendance drop off as a key concern that causes reluctance in employing lecture capture in the classroom. In a study which examined the association between lecture webcasts and student attendance, Traphagan et al. (2010) found that availability of webcasts negatively impacted student attendance. Owston et al. (2011) found that $10 \%$ of students stopped attending lectures when lecture capture was offered. Johnston et al. (2013) found a marked decrease in attendance by nursing students with access to captured lectures evident when compared to the previous year (from $80-85 \%$ down to $53 \%$ ), despite qualitative data that showed that students believed that watching videoed lectures was an ineffective replacement for face-to-face lectures.

There is also competing evidence that suggests lack of association between lecture capture and attendance. Brotherton and Abowd (2004) conducted a three-year study of lecture capturing at different universities and found that lecture capture did not have a negative effect on attendance. Herr et al. (2008) investigated the attendance records of close to 1,000 students over a two semester period and found that attendance was not significantly affected by their accessibility to recorded lectures. Von Konsky, Ivins, and Gribbl (2009) expressed the scepticism of academic staff towards student attendance in the presence of lecture capturing. However, their results suggest that attendance was not affected by lecture capturing. It is to be noted that regular taking of attendance during lectures could have encouraged students to attend class.

Despite the mixed results suggested by the prior literature regarding lecture capture and attendance, there is still a consensus that face-to-face lecture interaction is important in the learning process. Owston et al. (2011), discussed some of the advantages of lecture attendance as mentioned in prior studies. They state that lectures have informational richness, possess structure and allow for social interaction between students (Bassili, 2008, Brittain, 
Glowacki, Ittersum and Johnson, 2006, Copley, 2007, Dey, et al., 2009). Given the importance of attending lectures, we support the notion that lecture capturing does not impact class attendance. However, we suspect that differences in viewership exist between students with high attendance and students with low attendance. The following hypotheses state the proposed relationships.

\section{H3: High level of viewership of recorded lectures reduces class attendance.}

H4: Viewership of recorded lectures differs amongst high and low level attending students.

Student perception of lecture capturing is important for determining the usefulness of this technology (Andrews, et al., 2010, Euzent, et al., 2011, Ford, et al., 2012). Studies have been undertaken to explore the experiences and perceptions of different stakeholders involved in the introduction of recorded lectures. Zupancic and Horz (2002) studied students' behaviour using lecture recordings in a traditional computer science course. Their results showed that the more studious students spent more time using video recordings. Students who spent a lot of time working with lecture notes and attending tutorials also spent a lot of time with lecture recordings. Students who worked hard in a traditional course also worked hard with streamed recordings. Overall, students' behaviours did not change. In our opinion, this is typical of good students: they tend to take advantage of all resources and opportunities likely to improve their scholarship.

Dey, et al. (2009) studied the effects of offering online different versions of video lectures in comparison to the traditional classroom lectures in a physics course. They found that students had more positive perceptions of videoed lectures when accompanied by a videoed image of the lecturer, rather than having a slide presentation of lecture material that only included an audio of the lecturer. Preston, Phillips, Gosper, McNeill, Woo and Green 
(2010) investigated students' and academics' perspectives regarding the usage and impact of web-based lecture technology (WBLT) designed to digitally record lectures in four Australian universities. Students' responses indicated that they used the recordings to study for exams, review the lectures, and take notes from lectures. Students also pointed out that WBLT did not necessarily replace face-to-face lectures and they often 'doubled up' by attending lectures. Students reported that WBLT was a useful tool for learning, and a majority of students (76\%) had a positive experience with WBLT.

Andrews et al. (2010) evaluated students' perceptions on usage of recorded lectures in organic chemistry courses. Their study found that students had a positive perception of lecture recordings. Students reported the recordings as being very useful when they missed classes and also made a significant use of captured lectures even when they had been present in the classroom. Euzent et al.'s (2011) survey results suggested a positive perception of lecture capture by students in two large introductory economics course sections, specifically its flexibility and convenience. Brooks et al. (2011) investigated students' behaviour toward lecture capture, collecting data on their access patterns, and then exploring when and why those students used lecture capture systems. Survey responses showed that students liked recorded lectures because they could miss class when necessary, and the system allowed students to review materials. Gorissen, Van Bruggen and Jochems (2012) examined the use of recorded lectures by students enrolled in various courses at two universities. Participating students were asked to complete online surveys and to undergo semi-structured interviews. The results showed that most students watched the recorded lectures, using them as a replacement for missed lectures. They also used the recorded lectures for exam preparation.

We posit that students who perform better academically are more likely to express that they utilize lecture capturing relative to other students. Furthermore, we suspect that higher performing students tend to have a more positive perception of lecture capturing 
effectiveness when compared to other students. Finally, we predict that higher performing students do not perceive lecture capturing to be a substitute to class attendance when compared to other students. The following hypotheses pertain to student perception about lecture capture utilisation, effectiveness and impact on class attendance.

H5: The utilisation of lecture capture differs amongst top, medium and low performing students.

H6: Perceptions of lecture capture effectiveness differ amongst top, medium and low performing students.

H7: Perception of the impact of lecture capturing on attendance differ amongst top, medium and low performing students.

\section{Research Design}

\subsection{Sample Selection}

The sample used in this study consists of 254 first-year students enrolled in an introductory financial accounting course in Qatar in either the Fall Semester (2013) or the Spring Semester (2014). The course is of one semester duration and is offered in both Fall and Spring semesters. Hence the sampled students enrolled during the Fall Semester were different from those enrolled in the Spring Semester. Furthermore, the venue university does not use large lecture theatres for class meetings, instead students are placed in individual classes, also referred to as "sections", with each section comprising up to 50 students. In all, five sections were studied; three sections from students enrolled in Fall Semester and two sections from students enrolled in Spring Semester. Lecture capturing was introduced in Fall Semester. The three Fall Semester sections included a total of 152 students. The lectures were captured again during the Spring Semester for two new sections that included a total of 102 students. It is important to note that students across the five sections over the two semesters 
were taught by the same instructor, received the same material and were exposed to virtually the same teaching methods and learning resources. Finally, of the total sample, 98 were males and 156 were females.

Since lecture capturing was introduced to the course for the very first time in the Fall Semester, both the instructor and students had to adjust to the use of lecture capturing as a teaching and learning tool. The instructor had to become comfortable with being videotaped and learned to accept that a camera was a normal fixture in the classroom. Additionally, the instructor had to be mindful of issues affecting the accessibility of the captured lectures. For example, the instructor had to make sure that batteries in the portable microphone were always charged, otherwise the videos would have no audio. Another example was to make sure that every captured lecture was uploaded to Blackboard two hours after the completion of the lecture. Since there were three lectures a week, it was not uncommon, at the start of the Fall Semester, for the instructor to forget to upload some of the lectures. Students, on the other hand, were sceptical of the new tool. They initially had difficulties logging in and viewing the videos. They also raised concerns, early on in the Fall Semester, about the quality of the audio. However, by the end of the Fall Semester, many of the initial issues were successfully addressed thus leaving the instructor and students more comfortable with using lecture capturing technology than when it was first introduced.

Different students enrolled in the course during the Spring Semester, but the same instructor remained. Reflecting on the various situations and challenges experienced in the Fall Semester, the instructor was better equipped to guide the new set of students through their first exposure to lecture capturing. However, unlike students enrolled in the Fall Semester, Spring Semester students were more comfortable with the idea of lecture capturing. A possible reason could be that they received some insight from their peers who were enrolled during the Fall Semester. Perhaps the fact that this form of technology was 
becoming embedded in their educational environment eased any anxiety that the Spring Semester cohort might have had about their relatively new experience.

At the close of Spring Semester, students were asked to volunteer to take a survey with respect to lecture capturing. Consistent with other analyses in the study that categorized students into top, medium and low performing groups, students were asked to provide their university student number so that their performance and survey answers could be matched accordingly. It is important to acknowledge the undesirable effects resulting from the compromise of anonymity. Nevertheless, gaining an understanding of lecture capturing effectiveness and utilisation across different performance groups was of paramount importance to the study. It is also worth noting that prior studies such as Toppin (2011), Owston et al. (2011) and Soong, Chan, and Cheers (2006) used a similar approach in their surveys. Furthermore, the university's Institutional Review Board (IRB) was fully informed of the underlying process. To that effect, all university ethical requirements were obtained to proceed with the survey. In abiding by the IRB's request, a university staff member (other than the authors) distributed and collected the surveys. Students were informed verbally that their participation was voluntary and that their answers will have no bearing on how they will be assessed by the instructor. Additionally, the cover page of the survey clearly indicated that students could choose not to participate and that they could withdraw at any point. A copy of the survey can be found in the Appendix.

A total of 89 Spring Semester students provided feedback about the utilisation and effectiveness of lecture capturing. Out of the respondents, nine students stated that they did not use lecture capturing during the semester and thus did not answer the questions posed in the survey. Unreported T-test results suggest that the demographic details provided by those nine students, such as age, academic major and employment did not differ from the rest of the respondents. The final number of respondents was 80 students, 37 males and 43 females. 


\subsection{Performance, Viewership and Attendance}

Performance is represented by total grade in the course, GRADE. However, in order to gain a more in-depth understanding of academic achievement, the sample was split into top, medium and low performing students. On a scale of zero to 100, TOP referred to high performing students with grades ranging from 85 to 100. MED represented medium performing students who had grades from 65 to 84.9, and LOW represented low performing students who had grades below 64.9 and thus had either failed or had only achieved a lowlevel pass for the course. This categorization of student performance is largely based on the grading scale used in the venue university where $\mathrm{A}=$ above $90 ; \mathrm{B}+=85$ to $89.9 ; \mathrm{B}=80$ to 84.9; $\mathrm{C}+=75$ to $79.9 ; \mathrm{C}=70$ to $74.9 ; \mathrm{D}+=65$ to $69.9 ; \mathrm{D}=60$ to $64.9 ;$ and $\mathrm{F}=$ below 60 .

Recorded lectures were made available via Blackboard two hours after they were delivered in the classroom. Similar to Andrews et al. (2010), Blackboard tracking features were used to obtain records of student access to the captured lectures. The variable, VIEWERSHIP, represents the total number of attempts that each student made to view the lectures. There is an acknowledged weakness in this variable. Blackboard records show if a student has clicked on the link to the video (Andrews, et al., 2010), i.e., it shows number of "hits" to the link. However, it provides no confirmation that the student has actually viewed the lecture, either partially or completely. Instead it only reports the fact that an attempt was made to view the captured lectures. Various researchers have used the number of hits to measure viewership, for example, Johnston et al. (2013); Lewis and Sloan, (2012); McElroy and Blount, (2006); Prodanov, (2012); and Soong et al. (2006). This measure can be considered reliable under the assertion that the student would have logged on with the intention to view the recorded lectures.

The variable ATTEND represents student attendance and was measured as the percentage of attendance for the entire course. Attendance records were maintained regularly 
thereby allowing the instructor to keep accurate records of absenteeism. Student attendance was then split into two groups, high and low attendance, for further analysis. To produce these two sub-categories, the attendance median was calculated. Those students with attendance above the median were considered high attendance students while those that were below the median were considered low attendance students.

\subsection{Control variables}

Prior studies show that grade point average (GPA), gender and seniority play an important role in students' academic progress (Berg, Hughes, McCabe and Rayburn, 1995, Dillard-Eggers, Wooten, Childs and Coker, 2008, Stoner, 2009, Taghavi, 2006). The variable GPA was used to represent grade point average at the start of the semester. The venue university uses a 4.0 scale. The variable GENDER equalled "1" for females and "0" for males. Finally, the variable CREDIT was used to represent seniority. The variable was measured as the total course credits earned at the start of the course.

\subsection{Analysis}

The study used a combination of univariate and multivariate analyses to test the hypotheses that were introduced in the previous section. Analysis of variance (ANOVA) was used to test differences between group means for viewership and the other variables based on performance and to test mean differences in survey responses. ANOVA was also used to test differences in means for the test variables based on attendance. Since differences were tested based on sub-groups, Tukey's HSD post-hoc test was used to show which sub-groups differed from each other.

Multivariate analysis was conducted by estimating a regression model which related performance to viewership while controlling for attendance, GPA, gender, and seniority. The following section describes the details of the regression model.

\subsection{Regression Model}


We estimated a regression model which tested the relationship between performance and viewership:

$G A D E_{i}=\beta_{0}+\beta_{1}$ VIEWERSHIP $_{i}+\beta_{2}$ GENDER $_{i}+\beta_{3}$ ATTEND $_{i}+\beta_{4}$ CREDIT $_{i}+\beta_{5} G P A_{i}+\varepsilon_{t}$

where, $G R A D E_{, i}$ is the total grade in the course for the $i$ th student; VIEWERSHIP,$i$ is the number of attempts to view captured lectures as shown on Blackboard for the $i$ th student; $G_{E N D E R_{i}}$ is one if the $i$ th student is a female and zero otherwise; ATTEND $i$ is the percentage of classes attended by the $i$ th student; $C R E D I T_{i}$ is total course credits earned by the $i$ th student at start of the course; $G P A_{i}$ is the grade point average for the $i$ th student at the start of the course.

\section{Results}

The descriptive statistics for the variables used in the study are presented in Table 1. The average student results for the course across the two semesters were 76 out of 100 . Students averaged 14 attempts to access captured lectures. Females made up the majority of students and attendance was close to $84 \%$. Finally, students had an average of 34 credit hours at the start of the course. Due to the fact that the second semester (Spring Semester) witnessed improved implementation and information technology support vis-à-vis the first semester, the data set was split across semesters in order to examine whether changes occurred over the two semesters. The most significant change was in the number of attempts to view captured lectures as shown on Blackboard. An analysis of variance for the group means for VIEWERSHIP across the two semesters showed that they were statistically different, suggesting that more students utilized lecture capturing in the second semester relative to students in the first semester.

\section{Table 1: Descriptive Statistics}




\begin{tabular}{lrrrrrr}
\hline & N & Mean & Median & $\begin{array}{c}\text { Std. } \\
\text { Deviation }\end{array}$ & Minimum & Maximum \\
\hline All & & & & & & \\
GRADE & & & & & & \\
VIEWERSHIP & 254 & 76.17 & 80.00 & 17.93 & 1.60 & 100.00 \\
GENDER & 254 & 14.41 & 9.00 & 16.52 & 0.00 & 107.00 \\
ATTEND & 254 & 0.61 & N.A. & N.A. & N.A. & N.A. \\
CREDITS & 254 & 0.84 & 0.88 & 0.15 & 0.00 & 100.00 \\
GPA & 254 & 34.79 & 36.00 & 14.09 & 0.00 & 114.00 \\
\hline
\end{tabular}

\section{Fall Semester}

\begin{tabular}{lrrrrrr} 
GRADE & 152 & 77.34 & 80.00 & 17.74 & 10.00 & 100.00 \\
VIEWERSHIP & 152 & 11.46 & 7.00 & 13.55 & 0.00 & 81.00 \\
GENDER & 152 & 0.69 & N.A. & N.A. & N.A. & N.A. \\
ATTEND & 152 & 0.84 & 0.88 & 0.16 & 0.00 & 1.00 \\
CREDITS & 152 & 38.73 & 39.00 & 10.33 & 12.00 & 81.00 \\
GPA & 152 & 2.51 & 2.49 & 0.60 & 0.72 & 3.87 \\
\hline
\end{tabular}

Spring Semester

\begin{tabular}{lrrrrrr} 
GRADE & 102 & 74.43 & 80.00 & 18.15 & 1.60 & 99.50 \\
VIEWERSHIP & 102 & 18.81 & 14.00 & 19.39 & 0.00 & 107.00 \\
GENDER & 102 & 0.50 & N.A. & N.A. & N.A. & N.A. \\
ATTEND & 102 & 0.85 & 0.90 & 0.14 & 0.26 & 1.00 \\
CREDITS & 102 & 28.91 & 27.00 & 16.73 & 0.00 & 114.00 \\
GPA & 102 & 2.33 & 2.36 & 0.73 & 0.00 & 3.89 \\
\hline
\end{tabular}

Notes: GRADE = Total grade in the course, VIEWERSHIP = Number of attempts to view the captured lectures as shown on Blackboard, GENDER $=1$ for female and 0 for male (since gender is a categorical variable, the mean in this table represents the ratio of females to males), ATTEND = percentage of attendance for the entire course, CREDITS $=$ total course credits earned at start of the course, GPA $=$ Grade point average at the start of the course.

In order to obtain greater understanding of the descriptive statistics, performance was separated into three categories: Top, Med and Low. Table 2 presents ANOVA and Tukey HSD mean differences for the variables used in the study. The results in Table 2 suggest that VIEWERSHIP was different among the three performance groups. However, this difference was statistically significant only at the $10 \%$ level. A Tukey post-hoc test showed that the difference was between the low and medium performing groups. When splitting the data based on semesters, Table 2 shows that differences amongst the three groups were statistically significant (only at the 10\%) during Spring Semester, and not Fall Semester when lecture capturing was first introduced. Furthermore, the Tukey post-hoc test shows that the 
difference was between the top and low performing groups. It is important to note that during Spring Semester, the viewership mean for the top performing group was 24 while it was only 12 for the low performing group. Based on these results, we accept H1 (Viewership of recorded lectures differs amongst top, medium and low performing students) with the reservation that no differences were observed in the Fall Semester for viewership amongst top, medium and low performing students. Table 2 also shows that GENDER, ATTEND, CREDIT and GPA were statistically different for the three performance sub-groups. Furthermore, these differences were mainly between the LOW group on one hand and MED and TOP groups on the other. These differences sustained across semesters.

Table 2: Differences in Variables Based on Performance 


\begin{tabular}{|c|c|c|c|c|}
\hline \multirow[b]{2}{*}{ Variable } & \multirow[b]{2}{*}{ Performance } & \multirow[b]{2}{*}{ Mean } & \multirow[b]{2}{*}{ Std. Deviation } & \multirow{2}{*}{$\begin{array}{c}A N O V A \\
F\end{array}$} \\
\hline & & & & \\
\hline \multicolumn{5}{|c|}{ Panel A: All (n=254) } \\
\hline \multirow{3}{*}{ VIEWERSHIP } & Top & 15.40 & 18.37 & \multirow{3}{*}{$2.45^{*}$} \\
\hline & Med & 15.45 & 16.25 & \\
\hline & Low & 9.29 & 11.55 & \\
\hline \multirow{3}{*}{ GENDER } & Top & 0.72 & N.A. & \multirow{3}{*}{$7.36^{* * *}$} \\
\hline & Med & 0.61 & N.A. & \\
\hline & Low & 0.38 & N.A. & \\
\hline \multirow{3}{*}{ ATTEND } & Top & 0.90 & 0.09 & \multirow{3}{*}{$26.18 * * *$} \\
\hline & Med & 0.85 & 0.10 & \\
\hline & Low & 0.71 & 0.27 & \\
\hline \multirow{3}{*}{ CREDIT } & Top & 38.25 & 12.93 & \multirow{3}{*}{$15.17 * * *$} \\
\hline & Med & 35.62 & 14.74 & \\
\hline & Low & 24.76 & 9.63 & \\
\hline \multirow{3}{*}{$G P A$} & Top & 2.93 & 0.49 & \multirow{3}{*}{$105.61 * * *$} \\
\hline & Med & 2.34 & 0.46 & \\
\hline & Low & 1.64 & 0.57 & \\
\hline
\end{tabular}

\begin{tabular}{cc}
\hline Tukey HSD Mean Difference \\
\hline Top Low
\end{tabular}

\section{Panel B: Fall Semester (n=152)}

\begin{tabular}{llrrr}
\multirow{5}{*}{ VIEWERSHIP } & Top & 10.64 & 13.22 & \\
& Med & 13.73 & 14.95 & 2.272 \\
& Low & 7.21 & 8.55 & \\
\hline \multirow{3}{*}{ GENDER } & Top & 0.75 & N.A. & \\
& Med & 0.70 & N.A. & $2.676^{*}$ \\
& Low & 0.50 & N.A. & \\
\hline \multirow{3}{*}{ ATTEND } & Top & 0.89 & 0.09 & \\
& Med & 0.85 & 0.10 & $21.95^{* * *}$ \\
& Low & 0.67 & 0.29 & \\
\hline \multirow{3}{*}{ CREDIT } & Top & 41.87 & 10.14 & \\
& Med & 39.18 & 9.65 & $14.73^{* * *}$ \\
& Low & 29.50 & 7.00 & \\
\multirow{3}{*}{$G P A$} & Top & 2.93 & 0.44 & \\
& Med & 2.42 & 0.38 & $68.71^{* * *}$ \\
& Low & 1.73 & 0.55 & \\
\hline
\end{tabular}

\begin{tabular}{lll} 
Top & & 6.112 \\
Med & 0.056 & $6.168^{*}$ \\
& & \\
\hline Top & & $0.339^{* * *}$ \\
Med & 0.107 & $0.232^{* *}$ \\
& & \\
\hline Top & & $0.189^{* * *}$ \\
Med & $0.053^{* *}$ & $0.136^{* * *}$ \\
& & \\
\hline Top & \multirow{2}{*}{2.625} & $13.485^{* * *}$ \\
Med & & $10.860^{* * *}$ \\
\hline Top & & $1.294^{* * *}$ \\
Med & $0.587 * * *$ & $0.707^{* * *}$ \\
\hline
\end{tabular}

\begin{tabular}{lll} 
Top & & 3.431 \\
Med & 3.092 & 6.523 \\
& & \\
\hline Top & & $0.254^{*}$ \\
Med & 0.053 & 0.201 \\
& & \\
\hline Top & & $0.226 * * *$ \\
Med & 0.045 & $0.181^{* * *}$ \\
& & \\
\hline Top & \multirow{2}{*}{2.690} & $9.679 * * * *$ \\
Med & & \\
\hline Top & & $1.205^{* * * *}$ \\
Med & $0.515 * * *$ & $0.690^{* * *}$ \\
& & \\
\hline
\end{tabular}

Panel C: Spring Semester $(\mathbf{n}=102)$

\begin{tabular}{llrrl}
\multirow{2}{*}{ VIEWERSHIP } & Top & 24.47 & 23.11 & \\
& Med & 17.67 & 17.70 & $2.63^{*}$ \\
& Low & 12.06 & 14.45 & \\
\hline \multirow{3}{*}{ GENDER } & Top & 0.66 & N.A. & \multirow{2}{*}{$4.60^{* *}$} \\
& Med & 0.50 & N.A. & \\
& Low & 0.22 & N.A. & \\
\multirow{3}{*}{ ATTEND } & Top & 0.91 & 0.10 & \multirow{2}{*}{$6.67 * * *$} \\
& Med & 0.85 & 0.10 & \\
& Low & 0.77 & 0.24 & $4.59 * *$ \\
\multirow{3}{*}{ CREDIT } & Top & 31.34 & 14.91 & \\
& Med & 31.04 & 18.55 & \\
& Low & 18.44 & 9.12 & \\
\multirow{3}{*}{$G P A$} & Top & 2.93 & 0.58 & \\
& Med & 2.25 & 0.53 & $38.48 * *$ \\
& Low & 1.52 & 0.59 & \\
\hline
\end{tabular}

\begin{tabular}{lll} 
Top & & $12.413^{*}$ \\
Med & 6.796 & 5.618 \\
& & $0.434 * * *$ \\
Top & & $0.278^{*}$ \\
Med & 0.156 & $1.418^{* * *}$ \\
& & $0.753^{*}$ \\
\hline Top & & \\
Med & $0.066^{*}$ & $12.899 * *$ \\
& & $12.594 * *$ \\
\hline Top & & \\
Med & 0.305 & $1.413 * * *$ \\
& & $0.734 * * *$ \\
\hline Top & & \\
Med & $0.678 * * *$ & \\
& &
\end{tabular}

Notes: $* * *, * *$, and $*$ denote significant at the $1 \%, 5 \%$ and $10 \%$ levels.

Top $=$ High performing students that have grades from 85 to 100 , Med = Medium performing students that have grades from 65 to 84.9, Low $=$ Low performing students that have grades below 64.9. VIEWERSHIP $=$ Number of attempts to view the captured lectures as shown on Blackboard, GENDER $=1$ for female and 0 for male (since gender is a categorical variable, the mean in this table represents the ratio of females to males), ATTEND = percentage of attendance for the entire course, CREDITS = total course credits earned at start of the course, $G P A=$ Grade point average at the start of the course.

The full sample was separated into high and low attendance groups. This separation 
was based on attendance above and below the median. Students with attendance above the median were placed in the high attendance sub-set while those who attended below the median were in the low attendance group. Table 3 shows the mean viewership was 16 for the high group and 12 for the low group. The ANOVA results suggested that this difference was statistically significant at the $10 \%$ level. However, when separating the data based on semesters, viewership was statistically different between the two attendance groups only in Spring Semester. These results suggest that H4 (Viewership of recorded lectures differs amongst high and low level attending students) is accepted granted that no differences are observed in the Fall Semester.

Table 3: Differences in Variables Based on Attendance 


\begin{tabular}{|c|c|c|c|c|}
\hline \multirow[b]{2}{*}{ Variable } & \multirow[b]{2}{*}{ Attendance } & \multirow[b]{2}{*}{ Mean } & \multirow[b]{2}{*}{ Std. Deviation } & \multirow{2}{*}{$\begin{array}{c}A N O V A \\
F\end{array}$} \\
\hline & & & & \\
\hline \multicolumn{5}{|c|}{ Panel A: All $(n=254)$} \\
\hline \multirow{3}{*}{$G R A D E$} & High & 80.10 & 14.13 & \multirow{3}{*}{$14.80 * * *$} \\
\hline & Low & 71.60 & 20.69 & \\
\hline & All & 76.16 & 17.93 & \\
\hline \multirow{3}{*}{ VIEWERSHIP } & High & 16.21 & 16.57 & \multirow{3}{*}{$3.57 *$} \\
\hline & Low & 12.31 & 16.28 & \\
\hline & All & 14.41 & 16.52 & \\
\hline \multirow{3}{*}{ GENDER } & High & 0.66 & N.A. & \multirow{3}{*}{2.30} \\
\hline & Low & 0.56 & N.A. & \\
\hline & All & 0.61 & N.A. & \\
\hline \multirow{3}{*}{ CREDIT } & High & 35.15 & 13.85 & \multirow{3}{*}{0.20} \\
\hline & Low & 34.36 & 14.23 & \\
\hline & All & 34.79 & 14.09 & \\
\hline \multirow{3}{*}{$G P A$} & High & 2.56 & 0.61 & \multirow{3}{*}{$9.91 * * *$} \\
\hline & Low & 2.30 & 0.68 & \\
\hline & All & 2.44 & 0.66 & \\
\hline
\end{tabular}

Panel B: Fall Semester (n=152)

\begin{tabular}{|c|c|c|c|c|}
\hline \multirow{3}{*}{$G R A D E$} & High & 81.88 & 13.78 & \multirow{3}{*}{$11.85 * * *$} \\
\hline & Low & 72.30 & 20.23 & \\
\hline & All & 77.34 & 17.74 & \\
\hline \multirow{3}{*}{ VIEWERSHIP } & High & 12.56 & 11.59 & \multirow{3}{*}{1.12} \\
\hline & Low & 10.24 & 15.43 & \\
\hline & All & 11.46 & 13.55 & \\
\hline \multirow{3}{*}{ GENDER } & High & 0.73 & N.A. & \multirow{3}{*}{0.92} \\
\hline & Low & 0.65 & N.A. & \\
\hline & All & 0.69 & N.A. & \\
\hline \multirow{3}{*}{ CREDIT } & High & 40.28 & 10.39 & \multirow{3}{*}{$3.85 * *$} \\
\hline & Low & 37.01 & 10.05 & \\
\hline & All & 38.73 & 10.33 & \\
\hline \multirow{3}{*}{$G P A$} & High & 2.68 & 0.54 & \multirow{3}{*}{$13.78 * * *$} \\
\hline & Low & 2.33 & 0.61 & \\
\hline & All & 2.51 & 0.60 & \\
\hline
\end{tabular}

Panel C: Spring Semester (n=102)

\begin{tabular}{|c|c|c|c|c|}
\hline \multirow{3}{*}{$G R A D E$} & High & 77.72 & 14.82 & \multirow{3}{*}{$3.72 *$} \\
\hline & Low & 70.87 & 20.74 & \\
\hline & All & 74.43 & 18.15 & \\
\hline \multirow{3}{*}{ VIEWERSHIP } & High & 21.85 & 21.29 & \multirow{3}{*}{$2.75 *$} \\
\hline & Low & 15.53 & 16.70 & \\
\hline & All & 18.81 & 19.39 & \\
\hline \multirow{3}{*}{ GENDER } & High & 0.53 & N.A. & \multirow{3}{*}{0.348} \\
\hline & Low & 0.47 & N.A. & \\
\hline & All & 0.50 & N.A. & \\
\hline \multirow{3}{*}{ CREDIT } & High & 26.34 & 12.93 & \multirow{3}{*}{2.65} \\
\hline & Low & 31.69 & 19.81 & \\
\hline & All & 28.91 & 16.73 & \\
\hline \multirow{3}{*}{$G P A$} & High & 2.41 & 0.84 & \multirow{3}{*}{1.13} \\
\hline & Low & 2.25 & 0.59 & \\
\hline & All & 2.33 & 0.73 & \\
\hline
\end{tabular}

Notes: $* * *, * *$, and $*$ denote significant at the $1 \%, 5 \%$ and $10 \%$ levels.

Attendance $=$ High (1) if attendance percentage is above the median for total attendance percentage and Low (0) otherwise. Refer to Table 1 for definition of variables.

Since there are only two attendance categories (High \& Low), Tukey's post-hoc test is not needed.

A Pearson Correlation analysis was used to test the association between attendance 
and viewership. The results presented in Table 4 suggest that there was no negative relationship between attendance and viewing of recorded lectures. On the contrary, the results showed a slight positive relationship. However, when separating the data based on semesters, the relationship became insignificant, although the sign remained positive. These results indicate that $\mathrm{H} 3$ (High level of viewership of recorded lectures reduces class attendance) is rejected.

Table 4: Correlation Analysis for ATTEND and VIEWERSHIP

\begin{tabular}{|c|c|c|c|}
\hline & $\begin{array}{c}\text { All } \\
(n=254)\end{array}$ & $\begin{array}{c}\text { Fall } \\
(n=152)\end{array}$ & $\begin{array}{l}\text { Spring } \\
(\mathrm{n}=102)\end{array}$ \\
\hline Variable & ATTEND & ATTEND & ATTEND \\
\hline VIEWERSHIP & $0.137 *$ & 0.121 & 0.143 \\
\hline
\end{tabular}

The regression analysis results are presented in Table 5. The first model includes all data points and it shows that VIEWERSHIP and GRADE were positively related at the 5\% level. However, once other control variables were included into the model, the relationship became insignificant. A break-down based on semesters shows that VIEWERSHIP and GRADE were not related during Fall Semester. However, during Spring Semester, the relationship between VIEWERSHIP and GRADE was positive and significant at the $1 \%$ level in the basic model that included only those two variables, and at the $10 \%$ level in the multivariate model that included control variables. These results lead to the acceptance of $\mathrm{H} 2$ (Viewing recorded lectures improves student performance). However, we concede that the positive relationship was not observed for the two consecutive semesters. 
Table 5: Relationship between Performance and Viewership

\begin{tabular}{|c|c|c|c|c|c|c|c|c|c|c|c|c|}
\hline \multirow[b]{2}{*}{ Variables } & \multirow[b]{2}{*}{$\begin{array}{c}\text { Expected } \\
\text { Sign }\end{array}$} & \multicolumn{4}{|l|}{$A L L$} & \multicolumn{3}{|c|}{ Fall Semester } & \multicolumn{4}{|c|}{ Spring Semester } \\
\hline & & $\begin{array}{l}G R A D E \\
\text { (Exclude } \\
\text { controls) } \\
\end{array}$ & & $\begin{array}{l}\text { GRADE } \\
\text { (Include } \\
\text { controls) }\end{array}$ & & $\begin{array}{l}\text { GRADE } \\
\text { (Exclude } \\
\text { controls) } \\
\end{array}$ & $\begin{array}{l}\text { GRADE } \\
\text { (Include } \\
\text { controls) }\end{array}$ & & $\begin{array}{l}\text { GRADE } \\
\text { (Exclude } \\
\text { controls) }\end{array}$ & & $\begin{array}{l}G R A D E \\
\text { (Include } \\
\text { controls) } \\
\end{array}$ & \\
\hline VIEWERSHIP & + & $\begin{array}{l}0.139 \\
(2.236)\end{array}$ & $* *$ & $\begin{array}{c}0.031 \\
(0.790)\end{array}$ & & $\begin{array}{l}0.054 \\
(0.657)\end{array}$ & $\begin{array}{c}-0.014 \\
(-0.298)\end{array}$ & & $\begin{array}{c}0.297 \\
(3.110)\end{array}$ & $* * *$ & $\begin{array}{c}0.111 \\
(1.672)\end{array}$ & $*$ \\
\hline GENDER & $+/-$ & & & $\begin{array}{c}0.073 \\
(1.824)\end{array}$ & $*$ & & $\begin{array}{c}0.089 \\
(1.860)\end{array}$ & $*$ & & & $\begin{array}{c}0.055 \\
(0.805)\end{array}$ & \\
\hline ATTEND & + & & & $\begin{array}{l}0.310 \\
(7.455)\end{array}$ & $* * *$ & & $\begin{array}{c}0.230 \\
(4.241)\end{array}$ & $* * *$ & & & $\begin{array}{c}0.379 \\
(5.696)\end{array}$ & $* * *$ \\
\hline CREDIT & + & & & $\begin{array}{c}0.126 \\
(2.968)\end{array}$ & $* * *$ & & $\begin{array}{c}0.070 \\
(1.289)\end{array}$ & & & & $\begin{array}{c}0.192 \\
(2.838)\end{array}$ & $* * *$ \\
\hline$G P A$ & + & & & $\begin{array}{c}0.548 \\
(12.344)\end{array}$ & $* * *$ & & $\begin{array}{c}0.640 \\
(10.999)\end{array}$ & $* * *$ & & & $\begin{array}{c}0.465 \\
(6.657)\end{array}$ & $* * *$ \\
\hline $\mathrm{N}$ & & 254 & & 254 & & 152 & 152 & & 102 & & 102 & \\
\hline Adj. $R^{2}$ & & 0.016 & & 0.624 & & -0.004 & 0.665 & & 0.079 & & 0.592 & \\
\hline F-Stat & & 5.001 & $* *$ & 84.869 & $* * *$ & 0.432 & 60.823 & $* * *$ & 9.674 & $* * *$ & 30.365 & $* * *$ \\
\hline
\end{tabular}


A survey eliciting student feedback about the utilisation and effectiveness of lecture capturing was distributed to the students enrolled in the Spring Semester sections. This was a voluntary survey and the number of usable responses totalled 80 students. Questions One through Six focused on the utilisation of lecture capturing. The summary statistics are reported in Table 6. When asked about the period at which lectures were viewed, $75 \%$ of students responded that they viewed lectures during the same week that those lectures were presented in class. When the respondents were separated into the three performance groups, $91 \%$ of the low performing group indicated that they viewed lectures during the same week that those lectures were presented in class. ANOVA results suggest that there was a statistically significant difference amongst the three groups. A Tukey's post-hoc test indicates that the low and medium performing groups were different. It is important to note that a statistically significant difference was found amongst the three performance groups for the first question only (the period at which lectures were viewed). The remaining questions did not have statistically different results across the three groups. Additional analysis showed that $41 \%$ of students watched lecture captured videos only when it was close to exam week. While $63 \%$ of all students normally watched the full captured lecture video, only $48 \%$ fastforwarded to the needed sections. When asked about technical difficulties, only $16 \%$ answered that they experienced such problems. Finally, only $14 \%$ agreed with the statement that they attended fewer classes because they were able to watch the lecture captured videos at a later time. These results suggest in large that H5 (The utilisation of lecture capture differs amongst top, medium and low performing students) should not be accepted. 
Table 6: Survey Results - Utilisation of Lecture Capturing

\begin{tabular}{|c|c|c|c|c|c|c|c|c|c|c|c|}
\hline \multirow[b]{2}{*}{ Question } & \multirow[b]{2}{*}{ Performance } & \multirow[b]{2}{*}{$\mathbf{N}$} & \multirow[b]{2}{*}{ Mean } & \multirow[b]{2}{*}{ Median } & \multirow{2}{*}{$\begin{array}{l}\text { Std. } \\
\text { Deviation }\end{array}$} & \multirow[b]{2}{*}{ Minimum } & \multirow[b]{2}{*}{ Maximum } & \multirow{2}{*}{$\begin{array}{c}\boldsymbol{A N O V A} \\
F \\
\end{array}$} & \multicolumn{3}{|c|}{ Tukey HSD Mean Difference } \\
\hline & & & & & & & & & & Top & Low \\
\hline \multirow{4}{*}{ One } & All & 80 & 0.75 & 1.00 & 0.44 & 0.00 & 1.00 & \multirow{4}{*}{$3.20 * *$} & & & \\
\hline & Top & 28 & 0.86 & 1.00 & 0.36 & 0.00 & 1.00 & & Top & & 0.052 \\
\hline & Med & 41 & 0.63 & 1.00 & 0.49 & 0.00 & 1.00 & & Med & 0.223 & $0.275^{*}$ \\
\hline & Low & 11 & 0.91 & 1.00 & 0.30 & 0.00 & 1.00 & & & & \\
\hline \multirow{3}{*}{ Two } & All & 80 & 0.41 & 0.00 & 0.50 & 0.00 & 1.00 & \multirow{3}{*}{1.84} & & & \\
\hline & Top & 28 & 0.29 & 0.00 & 0.46 & 0.00 & 1.00 & & Top & & 0.078 \\
\hline & Med & 41 & 0.51 & 1.00 & 0.51 & 0.00 & 1.00 & & Med & 0.227 & 0.149 \\
\hline \multirow{4}{*}{ Three } & All & 80 & 0.63 & 1.00 & 0.49 & 0.00 & 1.00 & \multirow{4}{*}{0.28} & & & \\
\hline & Top & 28 & 0.61 & 1.00 & 0.50 & 0.00 & 1.00 & & Top & & 0.120 \\
\hline & Med & 41 & 0.61 & 1.00 & 0.49 & 0.00 & 1.00 & & Med & 0.003 & 0.118 \\
\hline & Low & 11 & 0.73 & 1.00 & 0.47 & 0.00 & 1.00 & & & & \\
\hline \multirow{4}{*}{ Four } & All & 80 & 0.48 & 0.00 & 0.50 & 0.00 & 1.00 & \multirow{4}{*}{0.69} & & & \\
\hline & Top & 28 & 0.43 & 0.00 & 0.50 & 0.00 & 1.00 & & Top & & 0.065 \\
\hline & Med & 41 & 0.54 & 1.00 & 0.50 & 0.00 & 1.00 & & Med & 0.108 & 0.173 \\
\hline & Low & 11 & 0.36 & 0.00 & 0.50 & 0.00 & 1.00 & & & & \\
\hline \multirow{2}{*}{ Five } & All & 80 & 0.16 & 0.00 & 0.37 & 0.00 & 1.00 & \multirow{2}{*}{0.06} & & & \\
\hline & Low & 11 & 0.18 & 0.00 & 0.40 & 0.00 & 1.00 & & & & \\
\hline \multirow{4}{*}{ Six } & All & 80 & 0.14 & 0.00 & 0.35 & 0.00 & 1.00 & \multirow{4}{*}{0.78} & & \multirow{4}{*}{0.099} & \\
\hline & Top & 28 & 0.07 & 0.00 & 0.26 & 0.00 & 1.00 & & Top & & 0.011 \\
\hline & Med & 41 & 0.17 & 0.00 & 0.38 & 0.00 & 1.00 & & Med & & 0.110 \\
\hline & Low & 11 & 0.18 & 0.00 & 0.40 & 0.00 & 1.00 & & & & \\
\hline
\end{tabular}

Notes:

***,**, and * denote significant at the $1 \%, 5 \%$ and $10 \%$ levels. The possible responses were 1 for yes and 0 for no. Refer to Table 1 for definition of variables.

Questions:

One: I watched the lecture captured video during the same week that the lecture was presented in class.

Two: I watched lecture captured videos only when it was close to exam week.

Three: I normally watched the full captured lecture video.

Four: I normally did not watch the full captured lecture. Instead I fast-forwarded to the needed sections.

Five: I experienced technical difficulties when accessing the lecture captured videos.

Six: I attended fewer classes because I was able to watch the lecture captured videos at a later time. 
The second part of the survey, questions Seven to Eleven, asked about the effectiveness of lecture capturing. The results are reported in Table 7 . Some $93 \%$ of all students claimed that lecture capturing helped them in clarifying concepts discussed in class and helped them study for exams. However, only $63 \%$ agreed with the statement that lecture capturing helped them in preparing for class discussions. Some $80 \%$ agreed with the statement that lecture capturing helped them enhance their exam results, while $74 \%$ said that lecture capturing increased their interest in the course. However, as shown in Table 7, the results did not statistically differ amongst the top, medium and low performing students and therefore H6 (Perceptions of lecture capture effectiveness differs amongst top, medium and low performing students) is rejected.

The final question in the survey focused on students' views regarding attendance. The results in Table 8 showed that only $15 \%$ of students agreed with the statement that lecture capturing served as a substitute for attending class. This was the only question where the three performance subgroups were statistically different. While only $7 \%$ of the top performing students seemed to agree with this statement, a staggering $64 \%$ of low performing students adopted the view that lecture capturing could be a substitute for class attendance. Given the results in Table 8, H7 (Perception of the impact of lecture capturing on attendance differ amongst top, medium and low performing students) is accepted. 
Table 7: Survey Results - Perceptions of Lecture Capture Effectiveness

\begin{tabular}{|c|c|c|c|c|c|c|c|c|c|c|c|c|}
\hline \multirow[b]{2}{*}{ Question } & \multirow[b]{2}{*}{ Performance } & \multirow[b]{2}{*}{$\mathbf{N}$} & \multirow[b]{2}{*}{ Frequency } & \multirow[b]{2}{*}{ Mean } & \multirow[b]{2}{*}{ Median } & \multirow{2}{*}{$\begin{array}{l}\text { Std. } \\
\text { Deviation }\end{array}$} & \multirow[b]{2}{*}{ Minimum } & \multirow[b]{2}{*}{ Maximum } & \multirow{2}{*}{$\begin{array}{c}A N O V A \\
F\end{array}$} & \multicolumn{3}{|c|}{ Tukey HSD Mean Difference } \\
\hline & & & & & & & & & & & Top & Low \\
\hline \multirow{4}{*}{ Seven } & All & 80 & $93 \%$ & 1.50 & 1.00 & 0.81 & 1.00 & 5.00 & \multirow{4}{*}{0.48} & & & \\
\hline & Top & 28 & $93 \%$ & 1.39 & 1.00 & 1.07 & 1.00 & 5.00 & & Top & & 0.062 \\
\hline & Med & 41 & $90 \%$ & 1.59 & 1.00 & 0.67 & 1.00 & 3.00 & & Med & 0.193 & 0.131 \\
\hline & Low & 11 & $100 \%$ & 1.46 & 1.00 & 0.52 & 1.00 & 2.00 & & & & \\
\hline \multirow{4}{*}{ Eight } & All & 80 & $93 \%$ & 1.51 & 1.00 & 0.84 & 1.00 & 5.00 & \multirow{4}{*}{0.14} & & & \\
\hline & Top & 28 & $93 \%$ & 1.46 & 1.00 & 1.07 & 1.00 & 5.00 & & Top & & 0.100 \\
\hline & Med & 41 & $90 \%$ & 1.56 & 1.00 & 0.74 & 1.00 & 4.00 & & Med & 0.097 & 0.106 \\
\hline & Low & 11 & $100 \%$ & 1.46 & 1.00 & 0.52 & 1.00 & 2.00 & & & & \\
\hline \multirow{4}{*}{ Nine } & All & 80 & $63 \%$ & 2.19 & 2.00 & 0.99 & 1.00 & 5.00 & \multirow{4}{*}{0.29} & & & \\
\hline & Top & 28 & $75 \%$ & 2.07 & 2.00 & 0.98 & 1.00 & 5.00 & & Top & & 0.010 \\
\hline & Med & 41 & $59 \%$ & 2.24 & 2.00 & 0.99 & 1.00 & 5.00 & & Med & 0.173 & 0.029 \\
\hline & Low & 11 & $46 \%$ & 2.27 & 3.00 & 1.10 & 1.00 & 4.00 & & & & \\
\hline \multirow{4}{*}{ Ten } & All & 80 & $80 \%$ & 1.80 & 2.00 & 0.99 & 1.00 & 5.00 & \multirow{4}{*}{0.82} & & & \\
\hline & Top & 28 & $82 \%$ & 1.61 & 1.00 & 0.99 & 1.00 & 5.00 & & Top & & 0.302 \\
\hline & Med & 41 & $78 \%$ & 1.90 & 2.00 & 1.00 & 1.00 & 5.00 & & Med & 0.295 & 0.007 \\
\hline & Low & 11 & $82 \%$ & 1.91 & 2.00 & 0.94 & 1.00 & 4.00 & & & & \\
\hline \multirow{4}{*}{ Eleven } & All & 80 & $74 \%$ & 1.96 & 2.00 & 1.05 & 1.00 & 5.00 & \multirow{4}{*}{0.40} & & & \\
\hline & Top & 28 & $79 \%$ & 1.82 & 1.00 & 1.22 & 1.00 & 5.00 & & Top & & 0.270 \\
\hline & Med & 41 & $73 \%$ & 2.02 & 2.00 & 0.94 & 1.00 & 5.00 & & Med & 0.203 & 0.067 \\
\hline & Low & 11 & $64 \%$ & 2.09 & 2.00 & 1.04 & 1.00 & 4.00 & & & & \\
\hline
\end{tabular}

Notes:

***, **, and * denote significant at the $1 \%, 5 \%$ and $10 \%$ levels. Frequency refers to the percentage of responses of "Agree" and "Strongly agree". The possible responses were: Strongly disagree $=1 ;$ Disagree $=2 ;$ Neutral $=3 ;$ Agree $=4 ;$ Strongly agree $=5$. Refer to Table 1 for definition of variables .

Question:

Seven: Lecture capturing helped in clarifying concepts discussed in class.

Eight: Lecture capturing helped me in studying for my exams.

Nine: Lecture capturing helped me in preparing for class discussions.

Ten: Lecture capturing helped me enhance my exam results.

Eleven: Lecture capturing increased my interest in the course. 
Table 8: Survey Results - Perceptions of Impact of Lecture Capture on Attendance

\begin{tabular}{|c|c|c|c|c|c|c|c|c|c|c|c|c|}
\hline \multirow[b]{2}{*}{ Question } & \multirow[b]{2}{*}{ Performance } & \multirow[b]{2}{*}{$\mathbf{N}$} & \multirow[b]{2}{*}{ Frequency } & \multirow[b]{2}{*}{ Mean } & \multirow[b]{2}{*}{ Median } & \multirow{2}{*}{$\begin{array}{l}\text { Std. } \\
\text { Deviation }\end{array}$} & \multirow[b]{2}{*}{ Minimum } & \multirow[b]{2}{*}{ Maximum } & \multirow{2}{*}{$\begin{array}{c}\boldsymbol{A N O V A} \\
F \\
\end{array}$} & \multicolumn{3}{|c|}{ Tukey HSD Mean Difference } \\
\hline & & & & & & & & & & & Top & Low \\
\hline & All & 80 & $15 \%$ & 3.74 & 4.00 & 1.10 & 1.00 & 5.00 & & & & \\
\hline Question & Top & 28 & $7 \%$ & 4.11 & 4.00 & 0.99 & 1.00 & 5.00 & & Top & & $0.925^{* *}$ \\
\hline \multirow[t]{2}{*}{ Twelve } & Med & 41 & $17 \%$ & 3.63 & 4.00 & 1.13 & 1.00 & 5.00 & $3.36 * *$ & Med & 0.473 & 0.452 \\
\hline & Low & 11 & $64 \%$ & 3.18 & 3.00 & 0.98 & 2.00 & 5.00 & & & & \\
\hline
\end{tabular}

Notes:

***, **, and * denote significant at the $1 \%, 5 \%$ and $10 \%$ levels. Frequency refers to the percentage of responses of "Agree" and "Strongly agree". The possible responses were: Strongly disagree $=1$; Disagree $=2 ;$ Neutral $=3$; Agree $=4$; Strongly agree $=5$. Refer to Table 1 for definition of variables .

Question Twelve: Lecture capturing served as a substitute for attending class. 


\section{Discussion and Conclusion}

Lectures are the dominant teaching method in most disciplines (Jones, 2007) and video recording technology, i.e., webcasting or podcasting, is ideally suited for this type of learning. The benefits of lecture capturing have been clearly highlighted in the literature (Brecht and Ogilby, 2008, Euzent, et al., 2011, Ford, et al., 2012, Gorissen, et al., 2012, Settle, et al., 2011, Traphagan, et al., 2010). However, the question of whether lecture capturing impacts student performance and attendance remains open for debate. We contribute to this discussion by examining the relationship between lecture capturing, student performance and class attendance for students registered in Introduction to Financial Accounting over two consecutive semesters (Fall and Spring Semesters).

As presented in the previous section, a slight positive relationship was observed between captured lecture viewership and performance. A closer examination revealed that the relationship was present in the Spring Semester only. A possible explanation is that by Spring Semester, lecture capturing was better embedded into the course. Although students enrolled in the Spring Semester were different than those enrolled in the Fall Semester, we suspect a learning curve due to possible peer-to-peer transference of knowledge. We believe that students from the Fall Semester could have easily shared their experience of lecture capturing with students from the Spring Semester. They could have even provided basic guidance with respect to accessing and operating captured videos. While no factual evidence exists to support our claims, some of the answers to the opened-ended questions in the survey could offer some insight. Several students had recommended the use of lecture capturing in other subjects offered at the venue university. It is plausible that those students, will at some point, speak about their lecture capturing experience with other students thereby, inadvertently, influencing their perception of this learning technology.

Another factor that could have influenced the overall environment in the course 
during the Spring Semester, with respect to lecture capturing, was the instructor. It is important to note that Introduction to Financial Accounting was taught by the same instructor during the Fall and Spring Semesters. Since the new technology was piloted in the Fall Semester, the instructor experienced several problems with its use and implementation. However, as the Fall Semester progressed, the instructor became more comfortable with operating the system and previously mentioned issues were all but resolved in time for Spring Semester.

The study also found that lecture capturing was not a substitute for attending classes. On the contrary, there was a slight positive correlation between class attendance and more viewership of captured videos. This could be interpreted that lecture capturing is a supplement to class attendance but not necessarily a substitute. It is important to note that some of the student comments in the open-ended questions suggest that lecture capturing helps immensely when classes are missed. Given these observations, it could be said that lecture capturing does not replace face-to-face interaction but it offers a tangible solution when extenuating circumstances occur which hinder students from coming to class. Our findings that viewership was higher for higher performing students are in line with the findings of Zupancic and Horz (2002), which showed that students who were more studious in a traditional course setting spent more time using recorded lectures.

Student perception of the new technology was of primary concern for us. Through the analysis of the survey given to students, we learned that students thought very highly of lecture capturing. Furthermore, the overwhelming majority of students stated that their understanding of the accounting subject and exam results improved due to viewing captured lectures. In terms of utilisation, little differences were observed for low, medium and top performing groups. There was only issue, which was the period in which the captured lectures were viewed by students. It seemed that Low performing students expressed that they 
had a greater tendency to watch the lecture captured video during the same week that the lecture was presented in class relative to other students. When asked whether lecture capturing served as a substitute for attending class, only $15 \%$ of the sample agreed or strongly agreed that it had that purpose. A closer examination of perceptions of lower performing students overwhelmingly thought otherwise (64\% agreed or strongly agreed). However, a distinction has to be made here between student perception and what actually transpired over the period of the study. Although some students might view lecture capturing as a substitute for face-to-face interaction, their attendance records reflect otherwise.

There are a number of limitations that need to be highlighted. Firstly, the independent variable, VIEWERSHIP, could be categorized as seemingly crude given its limited informative ability about the details of actual viewing patterns. Our study captured data on students' total viewership during the semester. Measuring the hits on individual lectures would provide more information about the type of user and perhaps also their reason for accessing the video. An alternative proxy for viewership would reveal the exact duration of each viewed lecture and whether the student paused, forwarded and rewound whilst viewing the lecture. Secondly, the sample size in the current study is very limited. Although all students over the two semesters were included in the current sample, a total of 254 students could be viewed by some as rather restricted. Future studies could address these shortcomings by testing a more powerful measure of VIEWERSHIP and increasing the sample size.

Future research can build on the methods and findings of the current study. An important area to examine is the impact of lecture capturing for the same set of students over multiple subjects. Although, observing students over a single semester is insightful, a more informative approach is to see how lecture capturing impacted the study habits, and even performance and attended for these same students.

In conclusion, this research contributes to the literature by providing empirical 
evidence and further insights for institutions seeking to implement innovative teaching pedagogies to meet modern students' learning preferences and to enhance student engagement and performance. Our findings of a slight positive relationship between lecture capture and performance are useful for institutions evaluating the benefits of an investment in this type of pedagogical enhancement. We found that engagement in the accounting subject advanced as the majority of students surveyed reported that their understanding improved through the use of lecture capture. This research has also provided further evidence to inform the debate about the effects of video capture on student attendance. Institutions with predominantly face-to-face learning pedagogies could question whether lecture capture is perceived as an off-campus option that perhaps substitutes for their traditional offerings. Our findings show that this is not the case. 


\section{References}

Andrews, C. J., Brown, R. C., Harrison, C. K., Read, D. and Roach, P. L. (2010) Lecture capture: Early lessons learned and experiences shared, New Directions, 6, pp. 56-60.

Barnes, K., Marateo, R. C. and Ferris, S. P. (2007) Teaching and learning with the net generation, Innovative Journal of Online Education, 3(4), pp. 1-8.

Bassili, J. N. (2008) Media richness and social norms in the choice to attend lectures or to watch them online, Journal of Educational Multimedia and Hypermedia, 17(4), pp. 453-75.

Berg, J. D., Hughes, J., McCabe, J. and Rayburn, K. (1995) Capital market experience for financial accounting students, Contemporary Accounting Research, 11(2), pp. 941-58.

Brecht, H. D. and Ogilby, S. M. (2008) Enabling a comprehensive teaching strategy: Video lectures, Journal of Information Technology Education Innovations in Practice, 7, pp. 71-86.

Brittain, S., Glowacki, P., Ittersum, J. and Johnson, L. (2006) Podcasting lectures, Educause Quarterly, 29(3), p. 24.

Brocato, J. (1989) How much does coming to class matter? Some evidence of class attendance and grade performance, Educational Research Quarterly, 13(3), pp. 2-6.

Brooks, C., Epp, C. D., Logan, G. and Greer, J. (2011) The who, what, when, and why of lecture capture, Paper presented at the 1st International Conference on Learning Analytics and Knowledge.

Brotherton, J. A. and Abowd, G. D. (2004) Lessons learned from eClass: Assessing automated capture and access in the classroom, ACM Transactions on ComputerHuman Interaction, 11(2), pp. 121-55.

Chang, S. (2007) Academic perceptions of the use of Lectopia : A University of Melbourne example ICT: Providing choices for learners and learning. Proceedings Ascilite (Singapore).

Copley, J. (2007) Audio and video podcasts of lectures for campus-based students: Production and evaluation of student use, Innovations in Education and Teaching International, 44(4), pp. 387-99.

Dey, E. L., Burn, H. E. and Gerdes, D. (2009) Bringing the classroom to the web: Effects of using new technologies to capture and deliver lectures, Research in Higher Education, 50(4), pp. 377-93.

Dillard-Eggers, J., Wooten, T., Childs, B. and Coker, J. (2008) Evidence on the effectiveness of on-line homework, College Teaching Methods \& Styles Journal, 4(5), pp. 9-16.

Duderstadt, J. J. (2001) The future of the university in the digital age, Proceedings of the American Philosophical Society, 145(1), pp. 54-72.

Euzent, P., Martin, T., Moskal, P. and Moskal, P. (2011) Assessing student performance and perceptions in lecture capture vs. face-to-face course delivery, Journal of Information Technology Education, 10(1), pp. 295-307.

Ford, M. B., Burns, C. E., Mitch, N. and Gomez, M. M. (2012) The effectiveness of classroom capture technology, Active Learning in Higher Education, 13(3), pp. 191201. 
Gorissen, P., Van Bruggen, J. and Jochems, W. (2012) Students and recorded lectures: survey on current use and demands for higher education, Research in Learning Technology, 20, pp. 297-311.

Herr, J., Bhatnagar, T., Goldfarb, S., Irrer, J., McKee, S. and Neal, H. A. (2008) University of Michigan lecture archiving and related activities of the U-M ATLAS Collaboratory Project, Paper presented at the Journal of Physics: Conference Series 119.

Holbrook, J. and Dupont, C. (2009) Profcasts and class attendance - Does year in program matter?, Bioscience Education, 13(from http://www.bioscience.heacademy.ac.uk/journal/vol13/beej-13-c2.pdf).

Holtzblatt, M. and Tschakert, N. (2011) Expanding your accounting classroom with digital video technology, Journal of Accounting Education, 29(2), pp. 100-21.

Johnston, A. N., Massa, H. and Burne, T. H. (2013) Digital lecture recording: A cautionary tale, Nurse education in practice, 13(1), pp. 40-47.

Jones, S. E. (2007) Reflections on the lecture: Outmoded medium or instrument of inspiration?, Journal of Further and Higher Education, 31(4), pp. 397-406 doi: 10.1080/03098770701656816.

Lewis, D. and Sloan, T. (2012) Using video capture technology to enhance student performance, Business Education Innovation Journal, 4(2), pp. 73-79.

Mayer, R. E. (2009) Multimedia Learning (2 ed.) (New York, NY 10013-2473, USA: Cambridge University Press).

Mayer, R. E., Heiser, J. and Lonn, S. (2001) Cognitive constraints on multimedia learning: When presenting more material results in less understanding, Journal of Educational Psychology, 93(1), pp. 187-98.

Mayer, R. E. and Moreno, R. (2003) Nine ways to reduce cognitive load in multimedia learning, Educational Psychologist, 38(1), pp. 43-52.

McElroy, J. and Blount, Y. (2006) You, me and ilecture 23rd Annual Ascilite Conference: Who's learning? Whose technology? (Sydney, Australia).

McNulty, J. A., Hoyt, A., Gruener, G., Chandrasekhar, A., Espiritu, B., Price, R. and Naheedy, R. (2009) An analysis of lecture video utilization in undergraduate medical education: Associations with performance in the courses, BMC Medical Education, 9(1), p. 6.

Mladenovic, R. (2000) An investigation into ways of challenging introductory accounting students' negative perceptions of accounting, Accounting Education: An International Journal, 9(2), pp. 135-55.

Nicholas, A. (2008) Preferred learning methods of the millennial generation, The International Journal of Learning, 15(6), pp. 27-34.

Owston, R., Lupshenyuk, D. and Wideman, H. (2011) Lecture capture in large undergraduate classes: Student perceptions and academic performance, The Internet and Higher Education, 14(4), pp. 262-68.

Paisey, C. and Paisey, N. J. (2004) Student attendance in an accounting module-reasons for non-attendance and the effect on academic performance at a Scottish University, Accounting Education: An International Journal, 13(Sup 1), pp. 39-53.

Preston, G., Phillips, R., Gosper, M., McNeill, M., Woo, K. and Green, D. (2010) Web-based lecture technologies: Highlighting the changing nature of teaching and learning, Australasian Journal of Educational Technology, 26(6), pp. 717-28.

Prodanov, V. I. (2012) In-class lecture recording: What lecture capture has to offer the instructor, Paper presented at the 2012 ASEE PSW Section Conference, Cal Poly, San Luis Obispo.

Secker, J., Bond, S. and Grussendorf, S. (2010) Lecture capture: Rich and strange, or a dark art? LSE Research Online available at http://eprints.lse.ac.uk/29184. 
Settle, A., Dettori, L. and Davidson, M. J. (2011) Does lecture capture make a difference for students in traditional classrooms?, Paper presented at the 16th annual joint conference on Innovation and technology in computer science education, Darmstadt, Germany.

Shaw, G. P. and Molnar, D. (2011) Non-native english language speakers benefit most from the use of lecture capture in medical school, Biochemistry and Molecular Biology Education, 39(6), pp. 416-20.

Singh, H. (2003) Building effective blended learning programs, Educational Technology, 43(6), pp. 51-54.

Soong, S. K. A., Chan, L. K. and Cheers, C. (2006) Impact of video recorded lectures among students, Paper presented at the 23rd Annual Ascilite Conference: Who's learning? Whose technology?, Sydney, Australia.

Stoner, G. (2009) Accounting students' IT application skills over a 10-year period, Accounting Education: An International Journal, 18(1), pp. 17-31.

Taghavi, S. E. (2006) The effects of age, access to a computer, and college status on computer attitudes, Journal of Information Technology Impact, 6(1), pp. 1-8.

Taplin, R. H., Low, L. H. and Brown, A. M. (2011) Students' satisfaction and valuation of web-based lecture recording technologies, Australasian Journal of Educational Technology, 27(2), pp. 175-91.

Toppin, I. (2011) Video lecture capture (VLC) system: A comparison of student versus faculty perceptions, Education Information Technology, 16, pp. 383-93.

Traphagan, T., Kucsera, J. V. and Kishi, K. (2010) Impact of class lecture webcasting on attendance and learning, Educational Technology Research and Development, 58(1), pp. 19-37.

Von Konsky, B., Ivins, J. and Gribble, S. (2009) Lecture attendance and web based lecture technologies: A comparison of student perceptions and usage patterns, Australasian Journal of Educational Technology, 25(4), pp. 581-95.

Wieling, M. B. and Hofman, W. H. A. (2010) The impact of online video lecture recordings and automated feedback on student performance, Computers \& Education, 54(4), pp. 992-98.

Wilson, P. and Wilson, C. (2010) About navigating accounting (http://www.navigatingaccounting.com).

Zupancic, B. and Horz, H. (2002) Lecture recording and its use in a traditional university course, ACM SIGCSE Bulletin, 34(3), pp. 24-28. 


\section{Appendix}

\section{Lecture capturing: Perception versus performance in an introductory accounting course}

You are invited to participate in this survey. The survey is specifically for students that registered in subjects that use lecture capturing. The survey is part of a research project that examines the relationship between lecture capturing and student performance. The survey should take around 10 minutes to complete.

Your participation in this study is completely voluntary. There are no foreseeable risks associated with this project. However, if you feel uncomfortable answering any questions, you can withdraw from the survey at any point. Your opinions are very important to the project.

Your survey responses will be strictly confidential and data from this research will be reported only in the aggregate. If you have any queries please contact the instructor at his university email.

Do you agree to continue: Yes No

If yes, please continue to the following page. 
DEMOGRAPHIC DATA

Please check appropriate responses

A. Your student number is:

B. Your Gender:

Male

Female

C. Your age is:

D. Over the semester you:

Did not have a job.

Had a job and worked part-time.

Had a job and worked full-time.

E. This subject is:

Part of the Major.

An elective.

A requirement for other programs.

None of the above.

F. Your Major is:

Accounting

Management Information Systems

Management

Finance

Marketing

None of the above

G. Your Minor is:

No minor selected

Accounting

Management Information Systems

Management

Marketing

Finance

Economics

None of the above 
Did you view lecture captured videos this semester?

$$
\begin{aligned}
& \square \text { Yes } \\
& \square \text { No }
\end{aligned}
$$

If you answered $\underline{\mathbf{Y e s}}$, then please continue. If you answered $\underline{\text { No}}$, then please go to question 15.

1. I watched the lecture captured video during the same week that the lecture was presented in class.

$$
\begin{gathered}
\square \text { Yes } \\
\square \text { No }
\end{gathered}
$$

2. I watched lecture captured videos only when it was close to exam week.

$$
\begin{aligned}
& \square \text { Yes } \\
& \square \quad \text { No }
\end{aligned}
$$

3. I normally watched the full captured lecture video.

$$
\begin{aligned}
& \square \text { Yes } \\
& \square \text { No }
\end{aligned}
$$

4. I normally did not watch the full captured lecture. Instead I fast-forwarded to the needed sections.

$$
\begin{aligned}
& \square \text { Yes } \\
& \square \text { No }
\end{aligned}
$$

5. I experienced technical difficulties when access the lecture captured videos.

$$
\begin{gathered}
\square \text { Yes } \\
\square \text { No }
\end{gathered}
$$

6. I attended fewer classes because I was able to watch the lecture captured videos at a later time.
Yes
No 
Please check the appropriate box $(\checkmark)$ which reflects your perceptions about lecture capturing. The Left hand side represents the negative extreme and the right hand side represents the positive extreme.

\begin{tabular}{|l|l|l|l|l|l|l|}
\hline & & $\begin{array}{l}\text { Strongly } \\
\text { Disagree }\end{array}$ & Disagree & Neutral & Agree & $\begin{array}{l}\text { Strongly } \\
\text { Agree }\end{array}$ \\
\hline $\mathbf{7}$ & $\begin{array}{l}\text { Lecture capturing helped in clarifying } \\
\text { concepts discussed in class. }\end{array}$ & & & & & \\
\hline $\mathbf{8}$ & $\begin{array}{l}\text { Lecture capturing helped me in studying for } \\
\text { my exams. }\end{array}$ & & & & & \\
\hline $\mathbf{9}$ & $\begin{array}{l}\text { Lecture capturing helped me in preparing for } \\
\text { class discussion. }\end{array}$ & & & & & \\
\hline $\mathbf{1 0}$ & $\begin{array}{l}\text { Lecture capturing helped me enhance my } \\
\text { exam results. }\end{array}$ & & & & & \\
\hline $\mathbf{1 1}$ & $\begin{array}{l}\text { Lecture capturing increased my interest in } \\
\text { the course. }\end{array}$ & & & & & \\
\hline $\mathbf{1 2}$ & $\begin{array}{l}\text { Lecture capturing served as a substitute for } \\
\text { attending class. }\end{array}$ & & & & & \\
\hline
\end{tabular}

14. What did you like MOST about the lecture capturing system?

15. What did you like LEAST about the lecture capturing system?

Thank you for your valuable feedback 